THURSDAY, JULY 13, I87 I

\section{THE NEXT TOTAL SOLAR ECLIPSE}

$\mathrm{I}^{\mathrm{T}}$ is infinitely to the credit of English men of science that they are at the present moment busily engaged in making arrangements for observations of the Total Solar Eclipse in December next, and it is extremely fortunate for the advance of Science that this rave phenomenonrare, that is, so far as the chance of observing it with moderate facility goes-occurs again just as the knowledge gleaned by the recent expeditions is being garnered to serve as a starting point for future inquiry.

When we state that the eclipse will be visible as a total one in India, Ceylon, and Australia, it may at first be imagined that in this case the facilities are not so very great. This would be quite true if it were necessary to garrison all these stations with observers from England; but, as it happens, the Governments both of India and Victoria have under their orders government astronomers -Mr. Pogson at Madras, and Mr. Ellery at Melbourne; and all that is necessary is to forward to those stations instructions, so that the observers there may glean all the experience gained in the last eclipse, and instruments such as are required to advance our present knowledge. And here we may remark that our knowledge in solar matters has recently advanced so rapidly, that astronomers have, as it were, to use new weapons in each attack, as artillery gives place to small arms, and small arms to the bayonet, in less scientific warfare.

That India and Australia will thus be provided with everything that may be necessary will be evident when we state that the Astronomer Royal is superintending the adaptation of instruments already in his possession for use in the former country, while the President of the Royal Society has already communicated with the authorities in Australia, offering to aid in every way in the proposed observations - an offer which we doubt not will be accepted, and in both cases we may hope for results of the highest importance, if the local observers set to work with a will. As to the entire sympathy of both governments there can be no question, India was magnificently helpful to Janssen in I 868 , and Australia has her spurs to win; and there are good men in plenty, in both places, in whom the Governments may place their fullest confidence.

There remains, then, Ceylon. Both the Royal and Royal Astronomical Societies have determined, if the Government will help, to send out a small party of observers from England to garrison this mid-station, which modern helps to travel have placed at our doors, and who knows that at one station or other Americans and Frenchmen may not be found to join in the good work? The new railway has made an American Expedition extremely easy.

And now let us enter a little more into particulars.

The central line of the eclipse will first meet the earth's surface in the Arabian Sea, and entering on the western coast of India, will pass right across one of the most important parts of Hindustan, in a S.E. by E. direction. In this part of the peninsula the sun will be about $20^{\circ}$ above the horizon when totally obscured. The duration of totality will be two minutes and a quarter, and the breadth of the shadow about seventy miles. On leaving the eastern coast of the Madras Presidency, the central line will cross Palk's Straits, passing about ten miles S.W. of the island Jaffnapatam, and over the northern part of Ceylon, where the small towns of Moeletivoe and Kokelay will lie near the central line; and also the well-known naval station of Trincomalee, which will be about fifteen miles S.W. of the line. Continuing its course over the Bay of Bengal, the shadow will cross the S.E. point of Sumatra, and will touch the south-western coast of Java, where Batavia, the capital, will lie nearly sixty miles N.E. of the central line ; and two other smaller towns, Chidamar and Nagara, will also be very near the middle of the shadow path. In the Admiralty Gulf, on the N.W. coast of Australia, the eclipsed sun will be only ten degrees past the meridian, and not far from the zenith; in consequence of which the totality will last $4^{\mathrm{m}} 18^{\mathrm{s}}$, or only four seconds less than the time of greatest duration. Lastly, passing through the most barren and uninhabited portion of Australia, crossing the Gulf of Carpentaria and the York Peninsula, the shadow will ultimately leave the earth's surface in the Pacific Ocean.

At present not too much is known about the chances of weather at any place; but what is known seems to point to a fair chance of success in both India and Ceylon, as the eclipse occurs during the N.E. monsoon; but, in any case, the experiences of the last Expedition show that for such a momentary phenomenon these chances noed scarcely be taken too seriously into consideration, seeing that where the finest weather was predicted a terrible pall of cloud covered the sky.

Next as to the work which the present state of our knowledge shows to be most desirable. This has been pointed out by Mr. Lockyer, in a communication to the Royal Society, and here we may in the main quote from his paper. Mr. Lockyer states : -

"In ray opinion the fundamental points of attack are : "a. Spectroscopic observations made with such an instrument as the one I took out to Sicily, equatorially mounted, and with reference spectra.

" $\beta$. Photographic observations made with such an instrument as the one I took out to Sicily, namely, a camera with large aperture and small focal length equatorially mounted. . . . .

"Perhaps I may clear the ground by stating what, in my opinion is comparatively UNIMPORTANT, so far as the crucial points are concerned, though to be tolerated if the crucial points are strongly taken up.

"a. Photographing prominences.

" $\beta$. Sketching anything but the changes in the corona.

" $\gamma$. Polariscopic observations.

" $\delta$. Observing Baily's Beads.

There should be one instrument, and Mr. Pogson could probably provide this in India, to determine the position of prominences before and after totality, During totality they should not be observed at all except incidentally.

"At each place (i.e., India, Ceylon, Australia) the spectroscopes should be employed for half an hour (to be on the safe side) before totality, in scrutinising the crescent at its narrowest place and the chromosphere outside the following limb of the moon.

"At each place, as before defined, there should be a spectroscope with a finder, and equatorial motion. 
(or some equivalent arrangement) directed to the sun's centre, to record any changes which take place in the spectrum from, say, half an hour before to half an hour after totality, and during totality, bien entendu. The relative darkness or brightness of the lines should be recorded every ten seconds.

"This spectroscope should have moderate dispersion, large object-glasses for collimator and telescope, and with focal length such that two or three degrees round the sun should be taken in (i.e., $\mathrm{I}^{\circ}$ or $\mathrm{I}_{2}^{1^{\circ}}$ from the sun's centre), and a large field.

"To come to the details of the expedition to Ceylon; I am of opinion that it need not exceed the following numbers, as my Sicilian experience has taught me that we may depend upon much valuable help from the officers at the place of observation :-

"I Telescope-Spectroscopic observer; 2 assistants.

"I Photographer; 2 assistants. This duty perhaps may be entrusted to skilled Sappers.

"I Spectroscopic observer; I assistant, or 8 in all.

"Among general observations, I would point out as being of extreme importance :

" $a$. Rays before, during, and after totality-their length, direction, and colour.

" $\beta$. Colours of the various layers of chromosphere, and of clouds and landscape. The order of these colours is of great importance.

" $\gamma$. Dark rays or rifts; whether they change, and whether they extend to the dark moon, or stop short above the denser layers of the chromosphere.

" $\delta$. The colours of the corona between bright or dark rays.

" $\epsilon$. All changes in corona.

" $\zeta$. Comparative brightness of rays and chromosphere and otter corona. . . . .

"In the above letter the nomenclature employed is the one I suggested in a recent lecture at the Royal Institution, namely :

"Corona, embracing the whole compound phenomenon outside the prominences (including rays and streamers), part of which is undoubtedly non-solar.

"Chromosphere, embracing the whole of the solar portion of corona, and all bright line regions outside the photosphere."

It is scarcely necessary to point out that the above deals with possibilities, rather than with desirabilities. We are convinced that a much larger party would do good work in Ceylon, but our scientific leaders are right in asking what our Government cannot refuse ; and, moreover, we may hope that the magnificent stations in India on the Neilgherries, at considerable elevations, will be strongly garrisoned, as they can well be by the eminent observers now in India.

We trust that these efforts to procure fresh observations will meet with the largest measure of success, for certainly the question of the Sun's Corona is the scientific question of the day. Once settle what is the real nature of the sun's surroundings, and the path of work is open for the more distant stars. So long as our knowledge of the sun is clouded by contending hypotheses, we cannot hope for real progress.

For our part we do not doubt that the Government will act as admirably as they did last year in the same branch of research when the requirements of Science are properly laid before them; and if the elements are equally kind, we may hope for a large increase of our knowledge.
TYNDALL'S "HOURS OF EXERCISE IN THE ALPS"

Hours of Exercise in the Alps. By John Tyndall, LL.D., F.R.S. (London : Longmans.)

THIS volume is a collection of short articles which have already seen the light in various publications, and are here thrown together, as the author says, "partly to preserve to myself the memory of strong and joyous hours, and partly for the pleasure of those who find exhilaration in descriptions associated with mountain life." Accordingly we find in it accounts of exciting scrambles, such as the Lawinenthor and the Old Weissthor, the first ascent of the Weisshorn, and the various assaults upon the Matterhorn, crowned at last with success. Of sadder interest are the story of the death of Benner, the professor's faithful guide, upon the Haut de Cry, contributed by one of the survivors; notices of the accidents on the Col de Geant and on the Matterhorn ; and, hardly less in interest though with happier ending, the rescue of a porter from the jaws of a crevasse on the great Aletsch Glacier, and the author's own hairbreadth escape on the Piz Morteratsch. All these are described with his usual graphic power and intense appreciation of natural scenery; sometimes in the philosophic vein, when a glass of whisky gives "a flash of energy," and even a ham sandwich can only be regarded as a conditioned form of potential muscular force; or sometimes in the more jubilant mood, when we are shown the grave professor "delighting to roll himself in a bubbling pool in some mountain stream, and afterwards dance himself dry in the sunshine."

Together with these sunny memories of alps and cascades, snow-fields and glaciers, there are some chapters of a more distinct scientific import, to which, as most germane to the pages of NATURE, we shall confine our notice. The first of these-the twentieth in the volume-is on Alpine Sculpture. The professor, we need hardly say, is a strong "Erosionist," attributing the valleys to the sculpturing influences of water, frost, and ice, as opposed to those who regard them as the result of fissures in the earth's crust produced by strains during its upheaval. His summary of the evidence for "sculpture $v$. fracture" strikes us as particularly good, and, as it happens, we can bear testimony from personal experience to the accuracy of the facts cited. He shows that by a simple geometric calculation, the width of the fissures produced by the upheaval of a hundred miles of the earth's crust to a maximum height of four miles would bear a very small ratio to the width of the existing valleys; therefore that the most which can be claimed for fissures is that they have guided the action of meteoric forces, have, as it were, drawn the rough sketch on the stone which has directed the picks of Nature's quarrymen, and guided the chisels of her sculptors. He points out that in the most fissure-like of gorges, such as those of the Via Mala or Pfäffers, characteristic water-marks are visible from top to bottom. His description of the latter may be taken as a summary of the evidence in these and many other cases which he has quoted. "Here the traveller passes along the side of the chasm, midway between top and bottom. Whichever way he looks, backwards or forwards, upwards or downwards, towards the sky or towards the river, he meets everywhere the irresistible and impressive evidence that this wonderful fissure has been sawn through the mountain by the 